\title{
Trace organic chemical attenuation during managed aquifer recharge: Insights from a variably saturated 2D tank experiment
}

\author{
Julia Regnery ${ }^{1,2^{*}}$, Jonghyun Lee ${ }^{3}$, Zachary W. Drumheller ${ }^{1}$, Jörg E. Drewes ${ }^{1,2}$, Tissa H. \\ Illangasekare ${ }^{1}$, Peter K. Kitanidis ${ }^{3}$, John E. McCray ${ }^{1}$ and Kathleen M. Smits ${ }^{1}$ \\ ${ }^{I}$ Department of Civil and Environmental Engineering, Colorado School of Mines, Golden, CO, USA \\ ${ }^{2}$ Chair of Urban Water Systems Engineering, Technical University of Munich, Garching, Germany \\ ${ }^{3}$ Department of Civil and Environmental Engineering, Stanford University, Stanford, CA, USA
}

*Corresponding author. Email address: jregnery@ mines.edu; phone: +1 3032733871.

Abstract

Meaningful model-based predictions of water quality and quantity are imperative for the designed footprint of MAR installations. A two-dimensional (2D) synthetic managed aquifer recharge system equipped with automated sensors (temperature, water pressure, conductivity, soil moisture, oxidation reduction potential) and embedded water sampling ports was used to test and model fundamental subsurface processes during surface spreading managed aquifer recharge (MAR) operations under controlled flow and redox conditions at the meso-scale. The fate and transport of contaminants in the variably saturated synthetic aquifer were simulated using the finite element analysis model, FEFLOW. In general, the model concurred with travel times derived from contaminant breakthrough curves at individual sensor locations throughout the 2D tank. However, discrepancies between measured and simulated trace organic chemical concentrations (i.e., carbamazepine, sulfamethoxazole, tris (2-chloroethyl) phosphate, trimethoprim) were observed. While the FEFLOW simulation of breakthrough curves captured overall shapes of trace organic chemical concentrations well, the model struggled with matching individual data points, although compound-specific attenuation parameters were used. Interestingly, despite steady-state operation, oxidation-reduction potential measurements indicated temporal disturbances in hydraulic properties in the saturated zone of the 2D tank that affected water quality. 
Keywords: Managed aquifer recharge, contaminant fate and transport, FEFLOW, sensors, oxidation reduction potential

\section{Introduction}

With dwindling water supplies in the United States and many regions worldwide, indirect potable reuse of impaired water sources (e.g., treated wastewater, stormwater runoff) is becoming an increasingly important component of water resource management. Managed aquifer recharge (MAR) is one important element in the multiple barrier concept of indirect potable reuse schemes that fulfills some or all of the following functions: (1) provide an opportunity to blend or dilute the impaired water; (2) increase the amount of time between the primary treatment of impaired water and its introduction into the water supply, and (3) decrease the concentration of microbial and chemical contaminants through physical, chemical, and microbiological attenuation processes in soils and groundwater (Drewes and Khan, 2011). However, the successful design and operation of MAR systems must be based on a sound understanding of hydrological, biological, and chemical processes, and their interactions, that are currently not understood sufficiently to provide useful predictions at all relevant scales of interest, especially regarding the attenuation of trace organic chemicals. A meaningful model-based prediction of water quality and quantity is imperative for the designed footprint of a MAR installation as evaluation of design concepts by build-and-test approaches at pilot- or full-scale is costly and time-consuming. Furthermore, baseline monitoring of an aquifer for several years before implementation may not be affordable for all MAR projects, or may not be feasible for approved projects with expiring budgets. Contaminant transport models may assist in better design and operation of MAR facilities, but it is essential that these models include important hydrogeochemical and biological processes influencing trace organic chemical fate and transport.

It has been suggested that automated sensing technologies that simultaneously monitor physical and chemical parameters at small-scale temporal and spatial resolution can help to correlate the response of microbial communities to key environmental conditions (e.g., temperature, $\mathrm{pH}$, dissolved oxygen (DO), nutrient availability, redox conditions) in soilaquifer systems (Shade et al., 2009; Regnery et al., 2013). But despite advances in environmental 'omics' research, the composition, interaction, and function of microbial 
communities linked to effective attenuation of trace organic chemicals is still an evolving field of research (Turnbaugh and Gordon, 2008; Shade et al., 2009; Johnson et al., 2015). Hence, simplifications are often made in order to capture complex microbiological functions and chemical reactions in numerical contaminant fate and transport simulations. Compoundspecific first-order biodegradation rate constants $(\lambda)$ are commonly used to describe biotransformation processes but they provide only a partial description of biodegradation processes if they neglect the temporal and spatial variability of key environmental parameters such as redox zonation in the subsurface. For a limited number of compounds redoxdependent $\lambda$ are available (e.g., Bertelkamp et al., 2014; Burke et al., 2014a; Regnery et al., 2015). However, transferring these soil column experiment derived $\lambda$ to field conditions can be challenging. Previous studies demonstrated that key parameter-dependent degradation rates, especially for redox-sensitive compounds, are required for contaminant transport modeling to properly capture the dynamics of trace organic chemical attenuation at the fieldscale (e.g., Greskowiak et al., 2006; Regnery et al., 2015; Henzler et al., 2016). Reactive multicomponent transport modeling (e.g., PHT3D coupling MT3DMS with PHREEQC-2) can be used to describe redox processes in artificial recharge systems, but rather complex biogeochemical reaction networks are required to simulate site-specific biogeochemical processes (Greskowiak et al., 2006 and references therein; Henzler et al., 2016).

Besides biotransformation, sorption on porous media surfaces is the most prevalent transport influencing process for most trace organic chemicals during MAR. To account for the various chemical and physical retardation mechanisms that are influenced by a wide range of variables, soil water distribution coefficients $\left(K_{d}\right)$ are empirically derived based on sorption isotherms at equilibrium (e.g., linear sorption isotherm, Freundlich isotherm). While $K_{d}$ can be related directly to soil organic carbon $\left(f_{o c}\right)$ content for many non-ionic compounds, several studies demonstrated that sorption of ionizable compounds (e.g., a variety of pharmaceuticals present in recycled water) to soil particles due to electrostatic interactions is highly influenced by factors such as soil $\mathrm{pH}$, mineral surface characteristics, cation exchange capacity (CEC), and the presence of clay minerals (e.g., Schaffer et al., 2012; Kodesová et al., 2015). Accordingly, retardation changes substantially depending on the composition of the aqueous and solid phase chemistry and generic or default $K_{d}$ values (i.e., $K_{d}$ values derived from organic carbon normalized sorption coefficients $K_{o c}$ ) can result in significant error when used to predict contaminant fate and transport. 
To address some of the important research needs, we designed and constructed a meso-scale two-dimensional (2D) synthetic managed aquifer recharge system equipped with automated sensors (temperature, water pressure, conductivity, soil moisture, oxidation reduction potential) and embedded water sampling ports to test and model fundamental subsurface processes under controlled flow and redox conditions that are more representative of surface spreading MAR operations compared to commonly used 1D soil column experiments. The main goal of the study was to provide a better understanding of trace organic chemical attenuation during MAR as a function of soil-aquifer conditions (e.g., $\mathrm{pH}$, redox, $f_{o c}, \mathrm{CEC}$ ) and compound-specific physicochemical properties (e.g., $K_{d}, \lambda$, charge). Selected indicator trace organic chemicals for this study were the antiepileptic drug carbamazepine, the antibiotics sulfamethoxazole and trimethoprim, the flame retardant tris (2-chloroethyl) phosphate (TCEP), and the antihistamine diphenhydramine. The computer program FEFLOW (Finite Element subsurface FLOW system, DHI-WASY, Berlin, Germany) was used for the 2D simulation of the fate and transport of contaminants in the variably saturated synthetic aquifer. In addition, we evaluated the use of automated sensing technologies to couple environmental parameters and contaminant transport in MAR systems.

\section{Materials and Methods}

\subsection{Selected model compounds}

All of the selected compounds show moderate to poor biodegradability in soil-aquifer systems (Wu et al., 2010a; Regnery et al., 2015) and represent a wide range of physicochemical properties (Table 1). Diphenhydramine and trimethoprim are weak bases and predominantly exist in their cationic form at $\mathrm{pH}$ conditions below their $p K_{a}$ values of 8.98 and 7.12, respectively. While TCEP is non-ionizable, carbamazepine is considered neutral within environmentally relevant $\mathrm{pH}$ ranges. Sulfamethoxazole is a weak acid and partially exists in the anionic form at neutral $\mathrm{pH}$. Due to electrostatic repulsion between the negatively charged compounds and negatively charged soil particle surfaces, anions adsorb less strongly to soil organic carbon than their neutral forms (Srinivasan et al., 2013).

\subsection{D synthetic aquifer configuration}

The 2D unconfined synthetic aquifer was designed and constructed at the Center for Experimental Study of Subsurface Environmental Processes (CESEP) at Colorado School of 
Mines. It was engineered out of a laminated fiberglass/plywood composite with a transparent acrylic front wall and a shape similar to the letter "L" that was rotated $90^{\circ}$ counterclockwise and mirrored about the vertical axis. The taller portion of the $2 \mathrm{D}$ tank served as the partially saturated infiltration zone, while the majority of the long horizontal section represented the unconfined saturated zone. The dimensions of the 2D tank were $4.88 \mathrm{~m}$ (length), $0.61 \mathrm{~m}$ (height unsaturated zone), $1.22 \mathrm{~m}$ (height fully saturated zone), $0.12 \mathrm{~m}$ (width), and $0.8 \mathrm{~m}^{3}$ (total volume), respectively. The detailed engineering drawings of the synthetic aquifer are provided in Drumheller (2015).

The configuration of the 2D synthetic aquifer for this study is shown in Figure 1. To prevent flow impediments due to clogging as experienced in preliminary tests using exclusively sandy soil from an active MAR site in Colorado, the tank was wet-packed with industrial silica sand (Granusil \#70, Unimin Corporation, Emmett, ID) as the main porous media in which defined blocks of sandy MAR soil (i.e., poorly graded sand with $4 \%$ fines, sifted through a $2 \mathrm{~mm}$ sieve) were incorporated. The basic chemical and physical properties of the soils used in this study were characterized using standard procedures at $20{ }^{\circ} \mathrm{C}$ laboratory temperature and are summarized in Table 2. The slightly more homogeneous properties of the industrial silica sand eased operation and predictive modeling of the 2D tank. The blocks of sandy MAR soil were solely intended as seed for microbial activity, and not as a heterogeneous flow domain. The saturated hydraulic conductivity of Granusil \#70 silica sand and the sandy MAR soil was determined to be $2.1 \times 10^{-4} \mathrm{~m} \mathrm{~s}^{-1}$ and $1.8 \times 10^{-4} \mathrm{~m} \mathrm{~s}^{-1}$, respectively (Table 2). The soil was carefully wet packed into the tank in $5 \mathrm{~cm}$ incremental depths to achieve a uniform bulk density by stirring and tamping the soil in accordance with the methods outlined in Sakaki and Illangasekare (2007). This approach has been shown to achieve good densities and prevent layering effects. Once packing of the tank was completed the top of the horizontal section was capped with laminated plywood and the acrylic front side was covered to minimize exposure to light.

Infiltration of dechlorinated tap water (City of Golden, $\mathrm{CO}$ ) from the top of the unsaturated zone through a Masterflex peristaltic pump (Cole-Parmer, Vernon Hill, IL) fed porous irrigation line started in October 2014. Dechlorination was achieved by recirculating the tap water inside a vented storage tank for at least 24 hours prior use. The constant head devices at the upstream and downstream boundaries of the synthetic aquifer were used to control the water table height as illustrated in Figure 1. After startup, the synthetic aquifer was brought to 
steady-state conditions with a constant infiltration rate of $0.3 \mathrm{~m} \mathrm{~d}^{-1}$ (i.e., total hydraulic loading rate of $315.8 \mathrm{~L} \mathrm{~m}^{-2} \mathrm{~d}^{-1}$ ) and a hydraulic gradient of 0.067 . The upstream constant head boundary was kept as no-flux boundary throughout this study. During experiments a second Masterflex peristaltic pump was used to spike tracer and trace organic chemicals, respectively into the tank's feed line at a defined ratio as described in section 2.5.

\subsection{Sensor technology and data acquisition}

The synthetic aquifer was equipped with 23 custom-built stainless steel water sampling ports, 13 custom-built porous cup tensiometers, 9 Decagon 5TE soil moisture, electrical conductivity, and temperature sensors (Decagon Inc., Pullman, WA), and 10 Cole-Parmer self-cleaning flat surface oxidation-reduction potential (ORP) probes. Clusters of sensors and sampling ports were distributed throughout the synthetic aquifer as indicated in Figure 1. Within each sensor cluster, sensors were spaced according to manufacturer's recommendation to not interfere with each other or adjacent sampling ports. Water sampling ports were located within a $5 \mathrm{~cm}$ radius of ORP sensors.

Porous cup tensiometers measure the water pressure in the soil by allowing water to pass through a porous ceramic cup $(4.45 \mathrm{~cm}$ length, $0.64 \mathrm{~cm}$ inner diameter, 0.5 bar air entry value, $6 \mu \mathrm{m}$ pore size; Soilmoisture Equipment Corp., Goleta, CA) and into a differential pressure transducer (PX26, wet/wet, 0-1 psi, \pm 0.01 psi accuracy; Omega, Stamford, CT). The pressure within the tensiometer was compared to atmospheric pressure in order to obtain the differential measurement. The 5TE sensor monitored bulk electrical conductivity $( \pm 10 \%$ accuracy at resolution of $\pm 0.01 \mathrm{dS} \mathrm{m}^{-1}$ from 0 to $7 \mathrm{dS} \mathrm{m}^{-1}$ and $\pm 0.05 \mathrm{dS} \mathrm{m}^{-1}$ from 7 to $23 \mathrm{dS}$ $\mathrm{m}^{-1}$ ), volumetric water content (accuracy of $\pm 0.01-0.02 \mathrm{~m}^{3} \mathrm{~m}^{-3}$ using medium specific calibration, resolution of $0.8 \times 10^{-3} \mathrm{~m}^{3} \mathrm{~m}^{-3}$ between $0 \%$ and $50 \%$ volumetric water content) and soil temperature $\left( \pm 1{ }^{\circ} \mathrm{C}\right.$ accuracy at $0.1^{\circ} \mathrm{C}$ resolution from -40 to $\left.60{ }^{\circ} \mathrm{C}\right)$. The ORP probe $( \pm 10 \mathrm{mV}$ accuracy) releases a differential voltage proportional to the ORP measured by an electrode at the tip of the sensor. The calibration procedures for all sensors are described in detail in Drumheller (2015). In brief, all of the porous cup tensiometers in the fully saturated zone of the 2D tank were calibrated in situ, whereas the two pressure sensors in the infiltration zone were calibrated in an external water column prior to installation. The accuracy of 5TE electrical conductivity and ORP probe measurements was validated using certified reference solutions. ORP probes were calibrated with $\mathrm{Ag} / \mathrm{AgCl}(4 \mathrm{M} \mathrm{KCl})$ reference solution at room 
temperature (Orion, Thermo Scientific, Waltham, MA) and readings were converted to reduction potential $\mathrm{E}_{\mathrm{h}}$. Electrical conductivity measurements of the 5TE sensors were converted to mass concentration by linear regression and volumetric water content measurements were calibrated according to the procedure outlined in Sakaki et al. (2011).

The porous cup tensiometers, 5TE sensors, and water sampling ports were installed through waterproof NPT fittings that were drilled and tapped into the acrylic front wall prior to wet packing of the tank. The ORP sensors were installed during wet packing of the tank. To minimize wall effects on measurements, sensors and sampling ports were positioned halfway between the rear and front walls of the tank. Subsequently, all tensiometers, 5TE sensors, and ORP probes were connected to a Campbell Scientific CR1000 data logger with an AM16/32 multiplexer (Logan, UT). The multiplexer was required to increase the number of sensors measured by the data logger. All of the tensiometers and ORP probes were wired into separate differential channels on the AM16/32 multiplexer. A single digital channel accommodated the data lines from all of the 5TE sensors as the CR1000 supported sensors that use SDI-12 protocol. During each experiment, data were acquired at specified time intervals and were stored on the data logger. Electrical conductivity, soil moisture, and temperature data was recorded from the nine 5TE sensors, ORP data was obtained from the 10 ORP probes, and pressure data was recorded from the thirteen porous cup tensiometers once every hour until experiments stopped in September 2015. A Matlab script was used to autonomously apply the respective calibration curves to sensor outputs when data were downloaded to a computer (Drumheller, 2015).

\subsection{Analysis of grab samples}

Water samples $(100 \mathrm{~mL})$ for analyses of organic and inorganic water quality parameters were collected from the 2D tank feed and selected intermediate sampling ports on a bi-weekly basis between January and April 2015. Analyses of organic and inorganic water quality parameters such as anions, cations, dissolved organic carbon (DOC), and ultraviolet absorbance at 254 nm (UVA) were carried out according to established Standard Methods (APHA, 2012). DO in the feed water and outflow of the synthetic aquifer was determined using a Hach HQ440d multi-parameter meter with an IntelliCAL optical DO probe. Electrical conductivity, $\mathrm{pH}$, and temperature in feed water samples were measured using an Oakton waterproof $\mathrm{pH} / \mathrm{CON} 300$ m (Oakton Instruments, Vernon Hill, IL). 
In addition, a total of 98 samples for the analysis of trace organic chemicals (Table 1) were collected from intermediate sampling ports \#3, \#4, \#5, \#6, \#9, \#10 and the 2D tank feed as outlined in section 2.5. Due to the required sample volume of $50 \mathrm{~mL}$, all of the sampled ports in this study were located in the saturated zone of the 2D tank. Samples were immediately preserved with sodium azide to minimize further biotransformation and were stored at $5{ }^{\circ} \mathrm{C}$ pending analysis ( $<72$ hours). Trace organic chemical analysis by solid phase extraction (Waters Oasis HLB cartridges, $500 \mathrm{mg}$ adsorbate, Milford, MA) and liquid chromatography coupled with tandem mass spectrometry (LC-MS/MS) in positive electrospray ionization mode was performed using isotope dilution (Teerlink et al., 2012). Compound-specific quantification limits for LC-MS/MS analysis were $5 \mathrm{ng} \mathrm{L}^{-1}$ (sulfamethoxazole), $10 \mathrm{ng} \mathrm{\textrm {L } ^ { - 1 }}$ (TCEP, trimethoprim), and $25 \mathrm{ng} \mathrm{L}^{-1}$ (carbamazepine, diphenhydramine).

\subsection{Sequence of tracer experiments}

Two conservative tracer tests using potassium bromide were conducted in November 2014 and September 2015 to gather electrical conductivity and pressure data that were used to calibrate the model simulations for the 2D synthetic aquifer. Potassium bromide solution was spiked for 13 hours during the first tracer test (November 2014) and 28 hours during the second tracer test (September 2015) resulting in a final concentration of $1 \mathrm{~g} \mathrm{~L}^{-1}$ potassium bromide in the pulse with an electrical conductivity of $1.2 \mathrm{dS} \mathrm{m}^{-1}$ (i.e., three times the background). After the pulse spike was completed (after 13 and 28 hours, respectively), the tracer solution was replaced with dechlorinated tap water for the remainder of the tracer test to maintain a constant infiltration rate of $0.3 \mathrm{~m} \mathrm{~d}^{-1}$. Each inorganic tracer test continued for 14 days to ensure that the conservative tracer passed all sensor locations that recorded electrical conductivity.

Starting January 2015, five indicator compounds (Table 1) were continuously spiked for six weeks at the $600 \mathrm{ng} \mathrm{L}^{-1}$ level to determine compound-specific breakthrough curves (BTC) at sampling locations \#3, \#4, \#5, \#6, and \#9. Samples were collected once or twice a day over a four-week period to capture the slope of each BTC. Subsequently, spiking was discontinued for three weeks to allow trace organic chemicals to be flushed from the $2 \mathrm{D}$ tank while infiltration continued. Spiking of all five trace organic chemicals reconvened in March 2015 at the $250 \mathrm{ng} \mathrm{L}^{-1}$ level to assess their fate in the 2D tank under established redox conditions in the unsaturated and saturated zone. After five weeks of continuous injection, triplicate 
samples for trace organic chemical analysis were collected in April 2015 from the 2D tank feed and sampling port locations \#3, \#4, \#5, \#6, \#9, and \#10. During experiments, trace organic chemical spiking solution was stored in an amber glass bottle at $5{ }^{\circ} \mathrm{C}$ and renewed every two days.

\subsection{Simulation of contaminant transport}

The fate and transport of contaminants in the variably saturated synthetic aquifer were simulated using the finite element analysis model, FEFLOW. FEFLOW solves the groundwater flow equation of both saturated and unsaturated conditions as well as mass and heat transport and includes chemical kinetics for multi-component reaction systems (Diersch et al., 2014). The general formulations of the mass and energy balance equations for FEFLOW are provided in Diersch et al. (2014). The model domain was discretized into 50,000 finite element grids and an adaptive time stepping approach was employed for accurate numerical simulations. The physical properties (e.g., $\phi, K)$, the boundary conditions for the domain (i.e., constant head or constant flux), and the initial conditions for each element (e.g., saturation) were fully defined. Steady-state initial flow condition for the flow and reactive transport simulation was obtained from a preliminary steady-state flow simulation using the same settings as detailed in section 2.2. The soil-water characteristic relationship for the unsaturated zone was defined using a spline curve fitted to the experiment data set. The advection-dispersion equation (including reversible linear and non-linear equilibrium sorption and first-order transformation) was solved to simulate spatial and temporal solute concentration changes in the synthetic aquifer. Travel time was determined based on BTC of solute at discrete locations (i.e., sensor clusters), by using the normalized temporal moments of the integrated BTC (Govindaraju and Das, 2007).

Reactive transport simulations were performed assuming constant concentration in the influx that corresponded to the experimental condition of spiked trace organic chemicals $(600 \mathrm{ng} / \mathrm{L}$ or $250 \mathrm{ng} / \mathrm{L}$, respectively); zero-dispersive flux condition at the outlet was imposed. Soilspecific (i.e., $\phi, K$ ), compound-specific (i.e., $K_{d}, \lambda$ ), and numerical parameters used for the flow and reactive transport modeling are provided in Tables 1 and 2. Besides literature derived values, $\lambda$ reflecting the redox conditions of the $2 \mathrm{D}$ tank were calculated from data collected during the second sampling campaign following a first-order decay model as described in Regnery et al. (2015). 


\section{Results and Discussion}

290

291

292

293

\subsection{Synthetic aquifer's hydrochemistry}

Selected steady-state water quality parameters analyzed throughout the synthetic aquifer are provided in Table 3. Throughout this study, the background electrical conductivity of the tap water used as the feed was in the range of $0.38 \pm 0.14 \mathrm{dS} \mathrm{m}^{-1}$. Nutrient limited conditions prevailed in the synthetic aquifer due to the low levels of DOC and nitrate and the absence of ammonia and phosphate in the feed water. However, an indication for biological activity in the synthetic aquifer was the reduction of dissolved oxygen $\left(\geq \Delta 2.8 \mathrm{mg} \mathrm{L}^{-1}\right)$ and DOC $(\Delta 0.5$ $\left.\mathrm{mg} \mathrm{L}^{-1}\right)$ and an increase in UVA $\left(\Delta 0.6 \mathrm{~m}^{-1}\right)$ and specific UV absorbance (SUVA; $\Delta 0.8 \mathrm{~L} \mathrm{mg}^{-}$ ${ }^{1} \mathrm{~m}^{-1}$ ). The increase in SUVA at sampling locations \#8 and \#10 pointed to the presence of dissolved organic matter with a higher degree of aromaticity. In general, microbial transformation of biodegradable DOC results in more recalcitrant substances with chromophoric characteristics. However, the limited availability of easily biodegradable DOC most likely created carbon-depleted conditions in the synthetic aquifer. The presence of $3 \mathrm{mg}$ $\mathrm{L}^{-1} \mathrm{DO}$ in samples collected from the $2 \mathrm{D}$ tank outflow (i.e., downstream constant head device) is at least partially related to the fact that DO was not measured in situ. Predominantly reducing conditions were established in the saturated zone of the synthetic aquifer. Low concentrations of dissolved manganese and dissolved iron were detected in the analyzed water samples (Table 3). This was corroborated by $E_{h}$ readings from embedded ORP probes in the saturated zone (Figure 2). Hargrave (1972) reported the absence of measurable DO concentrations in artificial sediment water systems as soon as $E_{h}$ values fell below $0.1 \mathrm{~V}$. This implies that oxygen is a subordinated controlling factor of $E_{h}$ in sediments. Interestingly, $E_{h}$ varied substantially at sensor locations \#7 and \#9 throughout the sequence of tracer experiments despite steady-state operation (Figure 2). In contrast, water pressure (Figure 2) and soil moisture sensors (data not shown) at sensor clusters recorded no variation among experiments. As the laboratory was temperature controlled, no distinct daily cycles were expressed in ORP and temperature readings. On average, recorded temperatures in the 2D tank at all sensor locations ranged between $20.0 \pm 1.1^{\circ} \mathrm{C}$ and $21.3 \pm 0.8^{\circ} \mathrm{C}$ during experiments.

\subsection{Hydraulic travel times}

The 5TE sensors detected the pulse spike of the inorganic conservative bromide tracer as it progressed through the synthetic aquifer during tracer tests in November 2014 and September 
2015. All nine sensors produced distinguished BTC of the tracer' electrical conductivity as shown in Figure 3. For model performance evaluation, the normalized temporal moments of the integrated BTC were calculated. The first normalized temporal moment of BTC determines the mean hydraulic travel time for each sensor location where the $\mathrm{n}$-th normalized temporal moment $\left(m_{n}\right)$ is defined as

$$
\mathrm{m}_{\mathrm{n}}=\frac{\int_{0}^{\infty} t^{n} C(x, t) d t}{\int_{0}^{\infty} C(x, t) d t}
$$

where $t$ is the elapsed time from the beginning of the tracer test, $C(x, t)$ is the tracer concentration at the location $x$ and time $t$. The first and second normalized temporal moments represent the mean tracer travel time and the amount of tracer plume spreading, respectively. These first two temporal moments provide an efficient way to summarize and quantify differences in modeling results and measurements (Barth et al., 2001).

As seen in Figure 4a, tracer experimental results were compared with FEFLOW simulations. While the model generally provided good results for sensor locations with mean travel times of less than 5 days, discrepancies became apparent for sensor locations \#6 and \#10 during the first tracer test in November 2014. For both sensor locations simulated travel times were approximately 1-2 days shorter than indicated by experimental BTC (Figures 3 and 4a). A better match was achieved during the second tracer test after we increased the duration of the pulse spike to 28 hours, resulting in more distinct BTC of the tracer' electrical conductivity at sensor locations \#6 and \#10. Thus, the overall fit between experimental and simulated travel times for the second tracer test $\left(\mathrm{R}^{2}=0.96\right)$ substantially improved in comparison to the first $\left(\mathrm{R}^{2}=0.89\right)$. Steady-state mean water pressure readings were in good agreement $\left(\mathrm{R}^{2}=0.97\right)$ with simulated water pressure throughout the synthetic aquifer (Figure 4b). During steadystate operation, sensor cluster \#1 was the only sensor cluster located in the unsaturated zone, all other clusters were situated in the saturated zone.

\subsection{Trace organic chemical breakthrough curves}

BTC for the trace organic chemicals carbamazepine, sulfamethoxazole, TCEP, and trimethoprim were measured for sensor clusters \#3, \#4, \#5, \#6, and \#9 (Figure 5). However, at sensor clusters \#4 and \#6 no samples were analyzed to capture the slope of the tail after continuous spiking stopped. Considering the porous media configuration of our synthetic 
aquifer with very low $f_{o c}<0.3 \%$ (Table 2 ), retardation through sorptive processes appeared to be dominated by electrostatic interaction between organic molecules and particle surfaces. Accordingly, almost no retardation was observed for carbamazepine (neutral charge), TCEP (uncharged), and sulfamethoxazole (negative charge) compared to the inorganic conservative bromide tracer, whereas diphenhydramine and trimethoprim (both positive charge) experienced significant retardation (Figure 5).

Travel through the short unsaturated zone (i.e., approximately $0.6 \mathrm{~m}$ ) under more oxidizing conditions had negligible impact on the fate and transport of carbamazepine and TCEP, whereas an effect was observed for sulfamethoxazole and trimethoprim. Hence, individual $\lambda$ for the unsaturated and saturated zone were applied in simulations to represent the prevailing redox conditions of the synthetic aquifer based on ORP readings and grab samples. Previous studies have shown that in carbon-depleted settings trimethoprim is preferentially removed under oxidizing conditions (Burke et al., 2014b; Regnery et al., 2015). The optimal redox condition for sulfamethoxazole, however, is disputed in literature (Henzler et al., 2014). For sulfamethoxazole, $\lambda$ were adapted from previous soil column experiments under controlled redox conditions (Regnery et al., 2015). For trimethoprim, $\lambda$ were derived from a study using groundwater but no soil during degradation batch experiments (Burke et al., 2014b) to minimize bias from dissipation based on electrostatic interaction. An increased $\lambda$ for the unsaturated compared to the saturated zone was applied in the FEFLOW simulations for sulfamethoxazole $\left(0.4 \mathrm{~d}^{-1}\right.$ and $0.049 \mathrm{~d}^{-1}$, respectively) and trimethoprim $\left(0.1 \mathrm{~d}^{-1}\right.$ and $0.01 \mathrm{~d}^{-1}$, respectively) to fit the shape of the experimental data (Figure 5). Considering that the synthetic aquifer had not been exposed to trace organic chemicals prior to the start of the experiment, a conservative assumption (i.e., no biotransformation irrespective of redox condition) was made for the more recalcitrant compounds carbamazepine, diphenhydramine, and TCEP in BTC simulations. Persistent behavior of carbamazepine and TCEP at the field scale was observed in multiple studies investigating bank filtration (e.g., Hoppe-Jones et al., 2010; Stepien et al., 2013). For the recalcitrant pharmaceutical diphenhydramine no breakthrough was observed or simulated at all sampled locations throughout the synthetic aquifer due to its predominantly positive charge at neutral $\mathrm{pH}$ and its high $K_{d}$ of $61 \mathrm{~L} \mathrm{~kg}^{-1}$ for sandy soil (Wu et al., 2010b). Diphenhydramine thus functioned as a process control.

Based on the BTC, discrepancies between observed and simulated trace organic chemical concentrations were evaluated by analyzing the first and second normalized temporal 
moments of the integrated BTC at the sensor locations. $\mathrm{R}^{2}$ values for carbamazepine, TCEP, and sulfamethoxazole were $0.92,0.89$, and 0.95 respectively (Figure 6). In general, model curves overshot measured data for sensor location \#4. At this sampling location, which is situated on the edge of the contaminant plume, a small error in the transport parameter assignment (e.g., dispersivity) associated with small-scale $K$ variability and model boundary conditions could have a significant impact. For trimethoprim, only three out of five temporal moment values were available for statistical analysis, which explains the lower $\mathrm{R}^{2}$ values (0.69 for $\mathrm{m}_{1}$ and 0.66 for $\mathrm{m}_{2}$ ) shown in Figure 6. While the FEFLOW simulation of BTC captured overall shapes of trace organic chemical concentrations well, the model struggled with matching individual data points. The calculated root mean square error for carbamazepine indicated an expected deviation of approximately $23 \%$ for individual measurements. However, some of the deviation in predicted concentration might be explained by variability in the measured data (e.g., precision of peristaltic pumps during spiking of environmentally relevant concentrations).

\subsection{Assessment of trace organic chemical fate}

The capability of the FEFLOW model to simulate contaminant fate and transport was further evaluated after the 2D tank was in operation for more than six months. Based on data gathered during the second sampling campaign, we estimated redox-dependent $\lambda$ for carbamazepine, sulfamethoxazole, and TCEP. As shown earlier, retardation by sorptive processes to silica sand was negligible for all three compounds. $\lambda$ were calculated for (1) the saturated zone representing predominantly reducing conditions and (2) the combined unsaturated and saturated zones (i.e., sequence of oxidizing and reducing conditions). Estimated $\lambda$ for carbamazepine, sulfamethoxazole, and TCEP were in the range of $0.033 \mathrm{~d}^{-1}\left(\mathrm{R}^{2}=0.95\right), 0.039$ $\mathrm{d}^{-1}\left(\mathrm{R}^{2}=0.79\right)$, and $0.011 \mathrm{~d}^{-1}\left(\mathrm{R}^{2}=0.80\right)$, respectively for the saturated zone and $0.035 \mathrm{~d}^{-1}\left(\mathrm{R}^{2}\right.$ $=0.97), 0.051 \mathrm{~d}^{-1}\left(\mathrm{R}^{2}=0.77\right)$, and $0.013 \mathrm{~d}^{-1}\left(\mathrm{R}^{2}=0.81\right)$, respectively for the combined unsaturated and saturated zones (Table 1). This corroborates the initial assessment that the short unsaturated zone in our synthetic aquifer had only a minor influence on the attenuation of carbamazepine and TCEP. Accordingly, simulations of carbamazepine and TCEP were performed using $\lambda$ of $0.035 \mathrm{~d}^{-1}$ and $0.013 \mathrm{~d}^{-1}$, respectively for both unsaturated and saturated zone, resulting in an acceptable fit between simulated and mean measured concentrations during the second sampling campaign (Figure 7). In contrast, sulfamethoxazole attenuation 
was affected by the short oxic soil passage, indicated by the increased $\lambda$ for the combined sequence of redox zones compared to predominantly reducing conditions. The simulation of sulfamethoxazole using a single $\lambda$ (i.e., $0.05 \mathrm{~d}^{-1}$ ) for both zones of the synthetic aquifer resulted in a poor fit between simulated and mean measured values as the model overestimated sulfamethoxazole concentrations (data not shown). Unfortunately no samples were collected from the unsaturated zone of the $2 \mathrm{D}$ tank over the course of this initial study to derive $\lambda$ solely representative of oxic conditions for sulfamethoxazole and trimethoprim. As a result, simulations were performed for both compounds during the second sampling campaign by using the redox-dependent $\lambda$ that had been adapted from literature (Table 1). As illustrated in Figure 7, a reasonable fit between simulated and mean measured concentrations was achieved for sulfamethoxazole $\left(\mathrm{R}^{2}=0.60\right)$ and trimethoprim $\left(\mathrm{R}^{2}=0.66\right)$ throughout the synthetic aquifer. Notably, at sensor cluster \#9 higher concentrations were measured for both compounds during the second sampling campaign than predicted by the model. In agreement with the simulated and measured trace organic chemical BTC for sensor cluster \#9 (Figure 5), the model overestimated trimethoprim travel time at this sampling location (Figure 7). As mentioned earlier, no significant differences in water pressure and saturation were observed at sensor locations \#1-9, implying a steady-state hydraulic gradient and water table throughout experiments. $\mathrm{E}_{\mathrm{h}}$ varied substantially at sensor location \#7, indicating reducing conditions during both inorganic tracer tests (November 2014 and September 2015) and more oxidizing conditions during trace organic chemical spiking (January through April 2015). More oxidizing conditions should have favored biotransformation of sulfamethoxazole and trimethoprim, however, the opposite was observed. We hypothesize that temporary preferential high-velocity flow channels in the rear upper part of the saturated zone (near the unsaturated zone) caused the mismatch of predicted and measured trace organic chemical concentrations at sampling location \#9. As microbiological and sorptive processes impact the attenuation of trimethoprim, a shorter and faster flow path through the synthetic aquifer resulted in less attenuation. Accordingly, almost no effect was observed for compounds with negligible $K_{d}$ and low $\lambda$ (i.e., minor change in concentration over time and distance) such as carbamazepine and TCEP.

The increased $\lambda$ for carbamazepine and TCEP during the second sampling campaign suggest that the microbial community in our synthetic aquifer was able to co-metabolize both compounds under carbon-depleted recharge conditions after an adaptation period of several 
weeks. For carbamazepine and TCEP, $\lambda$ in the range of $0-0.2 \mathrm{~d}^{-1}$ were reported in previous laboratory-scale studies (Burke et al., 2014a; Henzler et al., 2014; Regnery et al., 2015). However, we cannot exclude the presence of some small-scale physical non-equilibrium conditions in the 2D tank that the numerical model could not account for. To answer this question we will have to assign more accurate hydraulic conductivity distribution and corresponding dispersion parameters through the model parameter calibration (e.g., Lee et al., 2016) as well as screen water samples for transformation products by high-resolution mass spectrometry. However, this was beyond the capacity of this initial study.

\subsection{Impact of soil properties on contaminant transport}

Even though we used industrial silica sand as the main porous media in this study (very low $f_{o c}$ and CEC), the influence of sorptive processes on contaminant transport as a function of soil properties and the trace organic chemicals' physicochemical properties was distinct. Kodesová et al. (2015) had investigated pedotransfer rules, predicting the Freundlich sorption coefficients $\left(K_{F}\right)$ for carbamazepine, sulfamethoxazole, and trimethoprim in different soils, and proposed that these could be applied for prediction of pharmaceutical mobility in soils with similar soil properties. Findings of their study suggest that the sulfamethoxazole sorption coefficient is positively related to soil acidity, whereas the trimethoprim and carbamazepine sorption coefficients are positively related to soil organic matter, cation exchange capacity, and basic cation saturation (Kodesová et al., 2015). Their experimentally derived $K_{F}$ values $\left(\mathrm{cm}^{3 / \mathrm{n}} \mu^{1-1 / \mathrm{n}} \mathrm{g}^{-1}\right)$ ranged between 0.26 and 0.71 (carbamazepine), 0.11 and 1.39 (sulfamethoxazole), and 1.67 and 12.21 (trimethoprim) for soils that can likely be encountered at MAR sites such as sand (0\% clay, $0 \%$ silt, $100 \%$ sand, $\mathrm{pH} 8.7, f_{o c} 0.08 \%$, CEC $10.6 \mathrm{mmol}^{+}$ $\mathrm{kg}^{-1}$ ) and sandy soil (5\% clay, $11 \%$ silt, $84 \%$ sand, $\mathrm{pH} 5.4, f_{o c} 0.69 \%, \mathrm{CEC} 92.6 \mathrm{mmol}^{+} \mathrm{kg}^{-1}$ ) (Kodesová et al., 2015).

When we used these $K_{F}$ values for a 30-day flow simulation of the 2D tank assuming that the porous media of the physical system consisted of the respective soil type, breakthrough times for carbamazepine and sulfamethoxazole more than tripled in sandy soil compared to $100 \%$ sand due to slightly higher $f_{o c}$ and CEC, respectively. No breakthrough at any of the sensor locations was simulated for trimethoprim under these conditions. In good agreement, sandspecific $K_{F}$ values provided similar results as sand-specific $K_{d}$ values. This emphasizes the necessity of soil-specific partition coefficients for individual compounds or compound groups 
with similar physicochemical properties to be included in predictive contaminant transport modeling. Retardation due to electrostatic interaction between organic molecules and particle surfaces can be extensive. Although sites with substantial silt and clay contents are generally rejected for new MAR projects due to unfavorable hydraulic conditions (i.e., low hydraulic conductivity, increased clogging potential), small-scale subsurface heterogeneities are a common challenge, especially in alluvial flood plains (Parsekian et al., 2014; Regnery et al., 2016).

\subsection{Integration of sensor technologies}

As seen here and elsewhere, modern sensor based data acquisition approaches offer higher spatial and temporal resolutions than traditional field sampling methodologies. In addition, new sensors are being rapidly developed that provide novel and ever expanding possibilities for near real-time monitoring of key hydrogeochemical parameters. In the meso-scale synthetic aquifer continuous monitoring of the parameters water pressure, temperature, and electrical conductivity was essential to assure steady-state hydraulic conditions throughout experiments. However, the most valuable parameter in our study with regard to contaminant fate and transport was ORP. Although there are difficulties associated with the quantitative interpretation of ORP measurements and $\mathrm{E}_{\mathrm{h}}$ values, the measurements provide valuable information about important chemical and biological processes when used as a qualitative or operational parameter (Hargrave, 1972). The wide measurement range and high resolution of ORP probes allowed characterizing the oxidation-reduction state of the synthetic aquifer based on high or low $E_{h}$ values as well as monitoring changes thereof in near real-time. Thus, adequate $\lambda$ had been assigned for redox sensitive indicator compounds such as sulfamethoxazole and trimethoprim in the model.

It should be noted that sensor drift and biofouling remain challenges for the integration of sensor data into contaminant fate and transport modeling. For sensors that cannot be recalibrated in situ, replacement or numerical adjustment is mandatory. For the ORP sensors in our study, a slight drift of on average $4 \pm 3 \%$ or $8 \pm 6 \mathrm{mV}$, respectively across all 10 probes towards lower readings was observed after the sensors had been deployed in soil for a period of 8 months. When compared towards the reference calibration solution, 5 out of 10 ORP probes where slightly outside their accuracy range of $\pm 10 \mathrm{mV}$. The ORP probe that was deployed in the unsaturated zone showed the highest deviation (i.e., $-15 \mathrm{mV}$ ) from the original 
value. Nevertheless, the ORP sensors (as well as all other sensors) delivered satisfying quality data throughout the experiment.

Future work should focus on model adaptiveness, i.e., the ability to adjust predictions by assimilating data from sensors autonomously, to keep the model up-to-date regarding the inputs, the effect or management decisions (e.g., changes in hydraulic loading rate), and even the changing properties of the MAR system (e.g., clogging, biofilm growth). Continually updating integrated surface-subsurface system model parameters with sensor data can significantly improve the accuracy of model predictions and can compensate for the complexity of the physical flow and transport processes (Bandara et al., 2010; Barnhart et al., 2010).

\section{Conclusion}

The variably saturated 2D synthetic aquifer proved to be a valuable test bed to test and model fundamental subsurface processes at the laboratory meso-scale under controlled conditions. While travel through the short unsaturated zone of the 2D tank under more oxidizing conditions had negligible impact on the fate and transport of the anticonvulsant carbamazepine and the flame retardant TCEP, an effect was observed for the antibiotics sulfamethoxazole and trimethoprim. We demonstrated that using automated sensing technologies to couple environmental parameters and contaminant transport can help to correlate the complexity of trace organic chemical attenuation with potential drivers such as redox conditions within studied systems. This study also demonstrated that contaminant transport models depend on comprehensive high quality input data to perform well. Although the FEFLOW simulation of contaminant breakthrough curves in the 2D tank captured overall shapes of trace organic chemical concentrations well, the model struggled with matching individual data points, despite the fact that compound-specific attenuation parameters were used. More experimental work will be required to better incorporate different biotransformation and sorption processes into numerical simulations as a function of chemical structure and subsurface conditions as well as sensor data to characterize key parameters such as redox conditions in the subsurface. However, a combination of laboratory meso-scale and in situ testing in aquifers focusing on a set of indicator compounds with different physicochemical properties can help to overcome scale dependencies (i.e., differences 
between laboratory and field studies) and provide the information that is needed to specify MAR functions during design and implementation of MAR projects.

\section{Acknowledgement}

This study was supported by the National Science Foundation (NSF) Engineering Research Center for Reinventing the Nation's Water Infrastructure (ReNUWIt) under cooperate agreement EEC-1028968. We thank DHI-WASY for providing an educational license of FEFLOW for this study. We also thank A. Maul, P. Schulte, J. Smits, and former CESEP graduate students at Colorado School of Mines for their help with soil characterization, tank design, and construction.

\section{References}

American Public Health Association, 2012. Standard methods for the examination of water and wastewater, $22^{\text {nd }}$ ed. American Public Health Association, Washington, DC.

Bandara, V., Jayasumana, A.P., Pezeshki, A., Illangasekare, T.H., Barnhart, K., 2010. Subsurface plume tracking using sparse wireless sensor networks. EJSE 10, 1-10.

\section{Barnhart, K., Urteaga, I., Han, Q., Jayasumana, A., Illangasekare, T.H., 2010. On integrating} groundwater transport models with wireless sensor networks. Groundwater 48, 771-780.

Barth, G.R., Hill, M.C., Illangasekare, T.H., Rajaram, H., 2001. Predictive modeling of flow and transport in a two-dimensional intermediate-scale, heterogeneous porous medium. Water Resour. Res. 37, 2503-2512.

Bertelkamp, C., Reungoat, J., Cornelissen, E.R., Singhal, N., Reynisson, J., Cabo, A.J., van der Hoek, J.P., Verliefde, A.R.D., 2014. Sorption and biodegradation of organic micropollutants during river bank filtration: A laboratory column study. Water Res. 52, 231241.

Burke, V., Greskowiak, J., Asmuß, T., Bremermann, R., Taute, T., Massmann, G., 2014a. Temperature dependent redox zonation and attenuation of wastewater-derived organic micropollutants in the hyporheic zone. Sci. Total Environ. 482-483, 53-61.

Burke, V., Richter, D., Hass, U., Duennbier, U., Greskowiak, J., Massmann, G., 2014b. Redox-dependent removal of 27 organic trace pollutants: compilation of results from tank aeration experiments. Environ. Earth Sci. 71, 3685-3695. 
Darland, J.E., 1996. Arsenate mobility through a saturated sand: effects of pore water velocity, PH and phosphate competition. Master thesis. Montana State University, Bozeman, MT.

Diersch, H.-J.G., 2014. FEFLOW - Finite element modeling of flow, mass and heat transport in porous and fractured media. Springer, Berlin Heidelberg, 996p., doi:10.1007/978-3-64238739-5.

Drewes, J.E., and Khan, S.J., 2011. Water reuse for drinking water augmentation, in J.K. Edzwald (Ed.), Water Quality \& Treatment, 6th Edition. American Water Works Association, Denver, CO, chapter 16.

Drewes, J.E., Gerba, C.P., Snyder, S.A., Missimer, T., Regnery, J., Dickenson, E., 2015. Role of retention time in the environmental buffer of indirect potable reuse projects - An investigation on managed aquifer recharge. Report WRRF-10-05, WateReuse Research Foundation, Alexandria, VA.

Drumheller, Z.W., 2015. Development of a control optimization algorithm with uncertain parameter inversion for stochastic, nonlinear systems: A proof-of-concept applied to managed aquifer recharge and recovery. Master thesis. Colorado School of Mines, Golden, CO.

Govindaraju, R.S. and Das, B.S., 2007. Moment analysis for subsurface hydrologic applications. Water Science and Technology Library, Vol. 61. Springer Science \& Business Media. 296 pages.

Greskowiak, J., Prommer, H., Massmann, G., Nützmann, G., 2006. Modeling seasonal redox dynamics and the corresponding fate of the pharmaceutical residue phenazone during artificial recharge of groundwater. Environ. Sci. Technol. 40, 6615-6621.

Hargrave, B.T., 1972. Oxidation-reduction potentials, oxygen concentration and oxygen uptake of profundal sediments in a eutrophic lake. Oikos 23, 166-177.

Henzler, A.F., Greskowiak, J., Massmann, G., 2014. Modeling the fate of organic micropollutants during river bank filtration (Berlin, Germany). J. Contam. Hydrol. 156, 7892.

Henzler, A.F., Greskowiak, J., Massmann, G., 2016. Seasonality of temperatures and redox zonations during bank filtration - A modeling approach. J. Hydrol. 535, 282-292.

Hoppe-Jones, C., Oldham, G., Drewes, J.E., 2010. Attenuation of total organic carbon and unregulated trace organic chemicals in U.S. riverbank filtration systems. Water Res. 44, 4643-4659. 
623

624

625

626

627

628

629

630

631

632

633

634

635

636

637

638

639

640

641

642

643

644

645

646

647

648

649

650

651

652

653

654

655

656

657

658

659

660

661

662

663

Johnson, D.R., Helbling, D.E., Men, Y., Fenner, K., 2015. Can meta-omics help to establish causality between contaminant biotransformations and genes or gene products? Environ. Sci.: Water Res. Technol. 1, 272-278.

Kodesová, R., Grabic, R., Kocárek, M., Klement, A., Golovko, O., Fér, M., Nikodem, A., Jaksík, O., 2015. Pharmaceuticals' sorptions relative to properties of thirteen different soils. Sci. Total Environ. 511, 435-443.

Lee, J., Yoon, H., Kitanidis, P.K., Werth, C.J., Valocchi, A.J., 2016. Scalable subsurface inverse modeling of huge data sets with an application to tracer concentration breakthrough data from magnetic resonance imaging. Water Resour. Res. 52, 5213-5231.

Parsekian, A.D., Regnery, J., Wing, A.D., Knight, R., Drewes, J.E., 2014. Geophysical and hydrochemical identification of flow paths with implications for water quality at an ARR site. Groundwater Monit. R. 34, 105-116.

Regnery, J., Lee, J., Kitanidis, P., Illangasekare, T.H., Sharp, J.O., Drewes, J.E., 2013. Integration of artificial recharge and recovery systems for impaired water sources in urban settings: Overcoming current limitations and engineering challenges. Environ. Eng. Sci. 30, 409-420.

Regnery, J., Wing, A.D., Alidina, M., Drewes, J.E., 2015. Biotransformation of trace organic chemicals during groundwater recharge: How useful are first-order rate constants? J Contam. Hydrol. 179, 65-75.

Regnery, J., Wing, A.D., Kautz, J., Drewes, J.E., 2016. Introducing sequential managed aquifer recharge technology (SMART) - From laboratory to full-scale application. Chemosphere 154, 8-16.

Sakaki, T. and Illangasekare, T.H., 2007. Comparison of height-averaged and point-measured capillary pressure-saturation relations for sands using a modified Tempe cell. Water Resour. Res. 43, W12502, doi:10.1029/2006WR005814.

Sakaki, T., Limsuwat, A., Illangasekare, T.H., 2011. A simple method for calibrating dielectric soil moisture sensors: Laboratory validation in sands. Vadose Zone J. 10, 526-531.

Schaffer, M., Börnick, H., Nödler, K., Licha, T., Worch, E., 2012. Role of cation exchange processes on the sorption influenced transport of cationic $\beta$-blockers in aquifer sediments. Water Res. 46, 5472-5482. 
Shade, A., Carey, C.C., Kara, E., Bertilsson, S., McMahon, K.D., Smith, M.C., 2009. Can the black box be cracked? The augmentation of microbial ecology by high-resolution, automated sensing technologies. ISME J. 3, 881-888.

Srinivasan, P., Sarmah, A.K., Manley-Harris, M., 2013. Co-contaminants and factors affecting the sorption behaviour of two sulfonamides in pasture soils. Environ. Pollut. 180, 165172 .

Stepien, D.K., Regnery, J., Merz, C., Püttmann, W., 2013. Behavior of organophosphates and hydrophilic ethers during bank filtration and their potential application as organic tracers. A field study from the Oderbruch, Germany. Sci. Total Environ. 458-460, 150-159.

Teerlink, J., Hering, A., Higgins, C., Drewes, J.E., 2012. Variability of trace organic chemical concentrations in raw wastewater at three distinct sewershed scales. Water Res. 46, 32613271 .

Turnbaugh, P.J. and Gordon, J.I., 2008. An invitation to the marriage of metagenomics and metabolomics. Cell 134, 708-713.

Wu, C., Spongberg, A.L., Witter, J.D., Fang, M., Czajkowski, K.P., Ames, A., 2010a. Dissipation and leaching potential of selected pharmaceutically active compounds in soils amended with biosolids. Arch. Environ. Contam. Toxicol. 59, 343-351.

Wu, C., Spongberg, A.L., Witter, J.D., Fang, M., Czajkowski, K.P., 2010b. Uptake of pharmaceuticals and personal care products by soybean plants from soils applied with biosolids and irrigated with contaminated water. Environ. Sci. Technol. 44, 6157-6161. 


\section{Graphical abstract:}

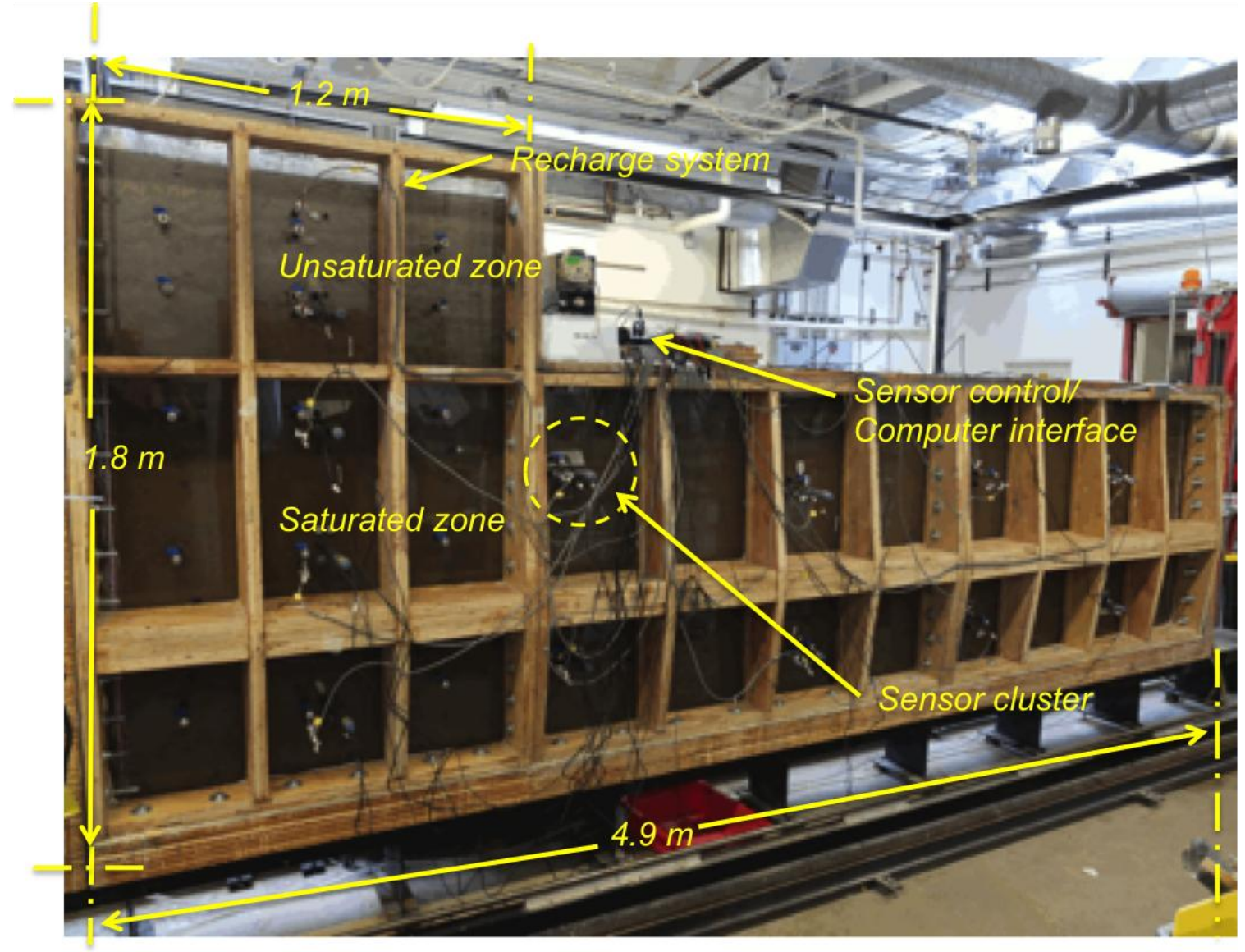




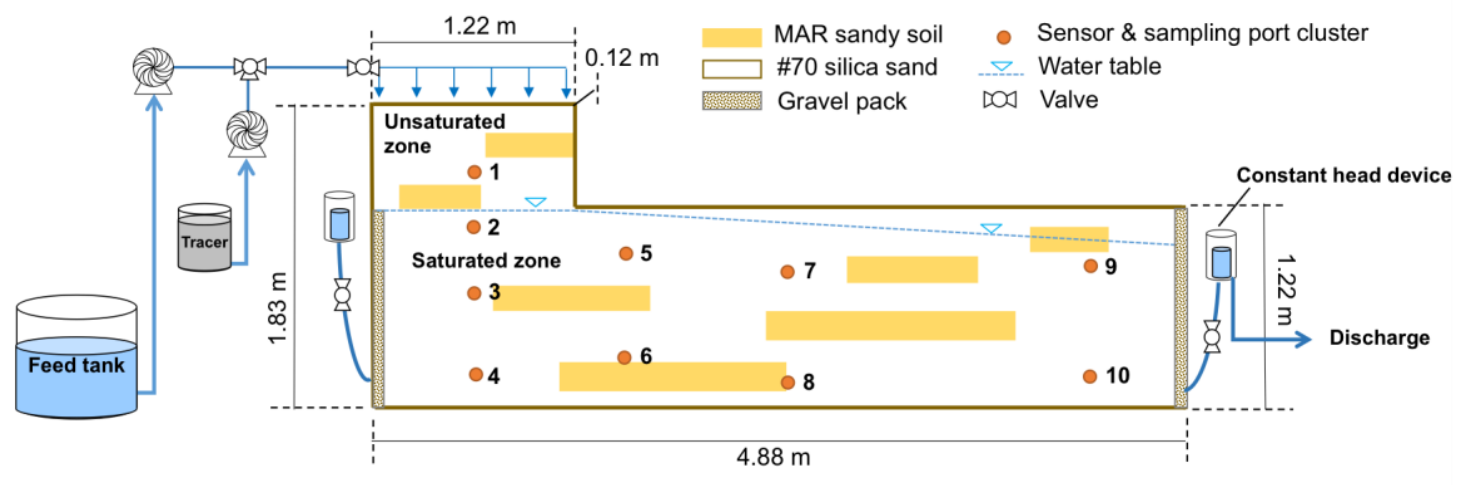

Figure 1. Schematic of the unconfined 2D synthetic aquifer. All sensors are wired to a data logger. Note that in all experiments the upstream constant head boundary was converted to a no-flux boundary by closing the valve. 
Figure 2


Figure 2. Measured steady-state water pressure (left) and reduction potential $E_{h}$ (right) of individual sensor clusters during experiments (January - April 2015). See Figure 1 for sensor locations. 

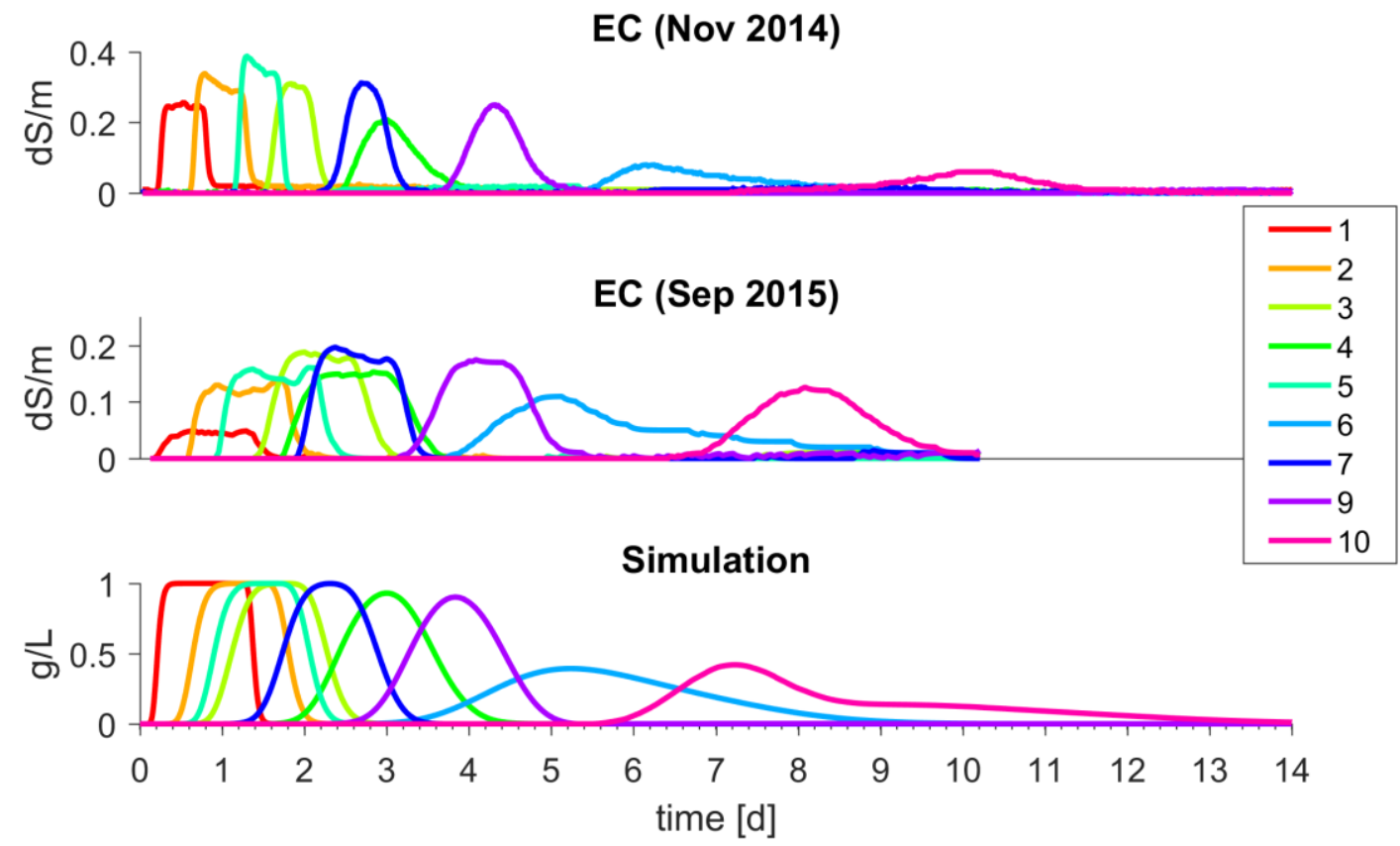

Figure 3. Observed and simulated travel time of the conservative inorganic tracer at all sensor locations of the synthetic aquifer during experiments in November 2014 and September 2015. See Figure 1 for sensor locations. 
(a)

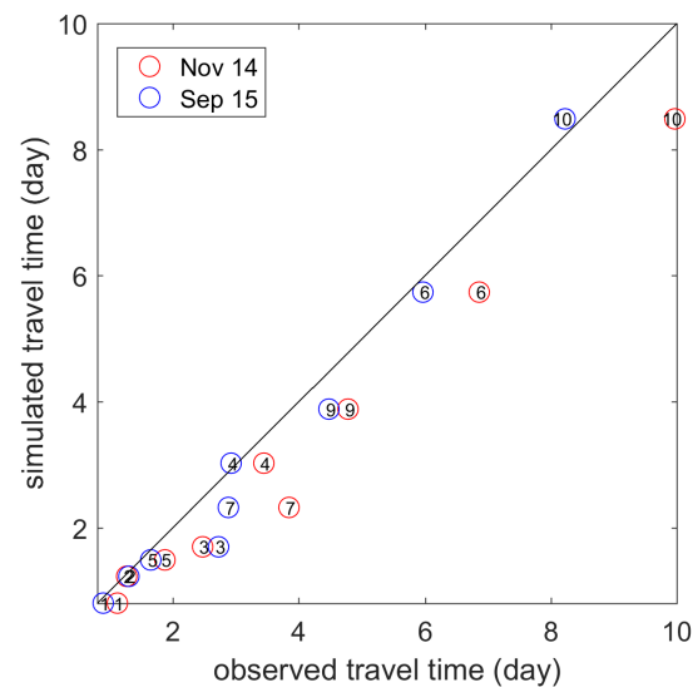

(b)

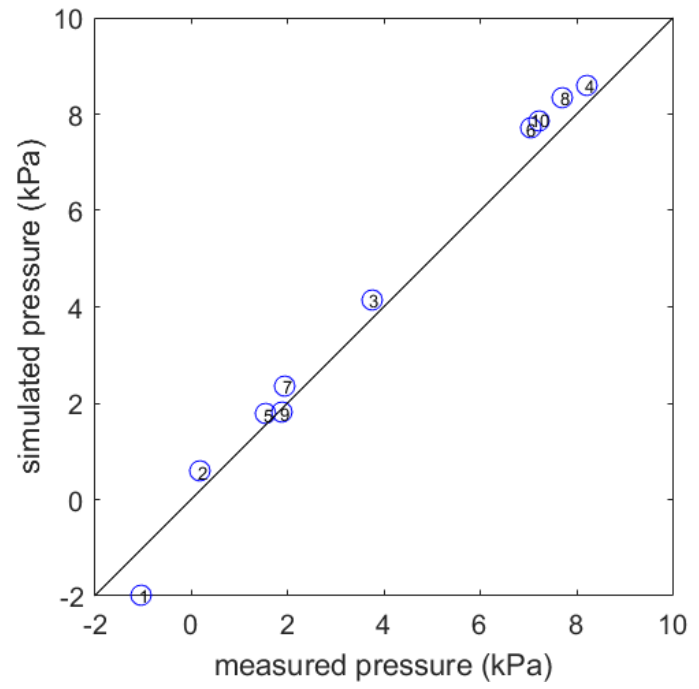

Figure 4. Comparison of (a) observed vs. simulated travel time of the conservative inorganic tracer at all sensor locations of the synthetic aquifer during experiments in November 2014 (red circles, $\mathrm{R}^{2}=0.89$ ) and September 2015 (blue circles, $\mathrm{R}^{2}=0.96$ ) and (b) simulated and measured steady-state water pressure data at sensor locations $\left(\mathrm{R}^{2}=0.97\right)$. 


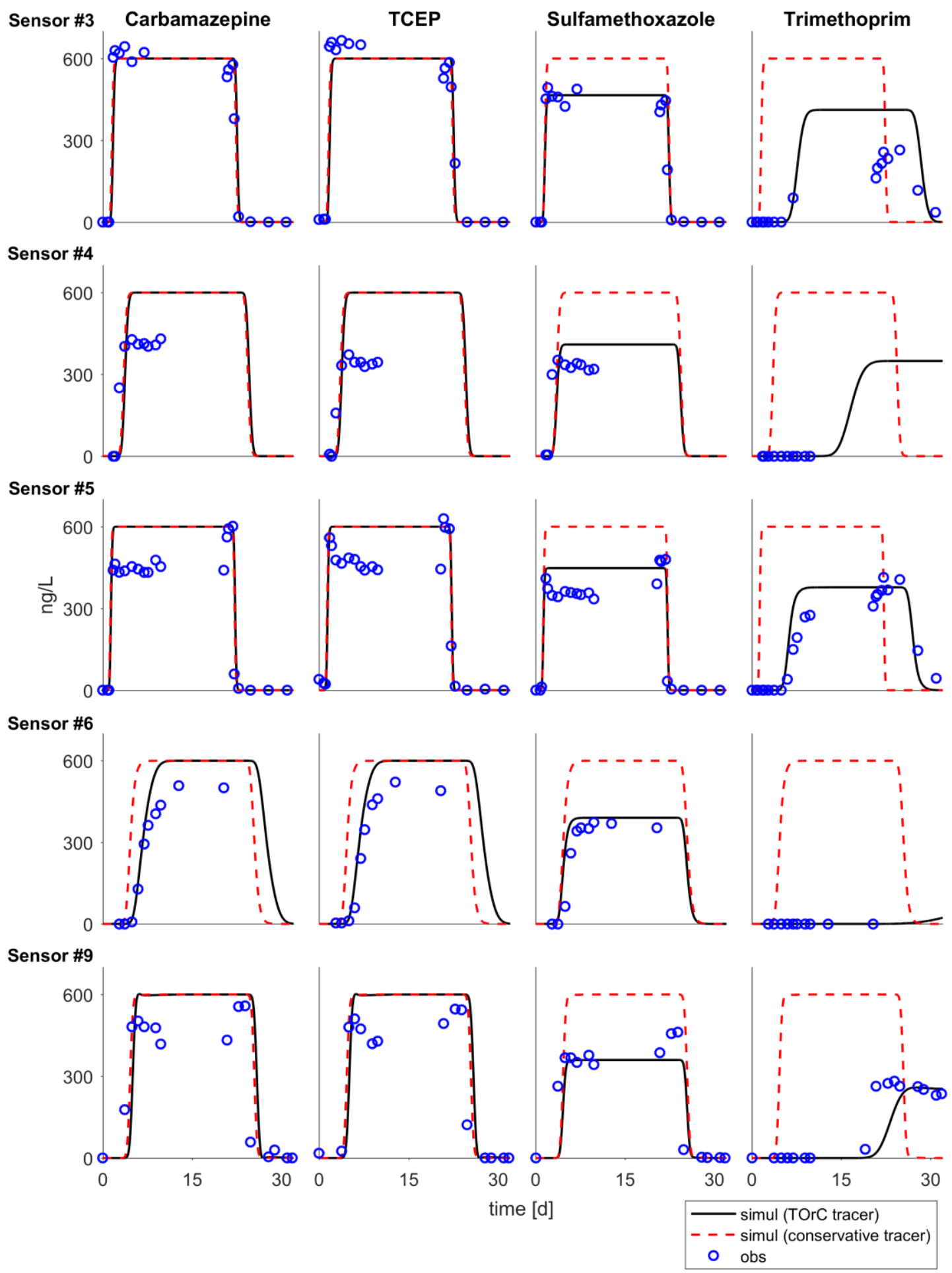

Figure 5. Measured (blue circles) and simulated (black line) breakthrough curves (BTC) of the trace organic chemicals carbamazepine, TCEP, sulfamethoxazole, and trimethoprim at sensor clusters \#3, \#4, \#5, \#6, and \#9. Simulated BTC assuming conservative transport are shown as red dotted line. See Figure 1 for sensor locations. 

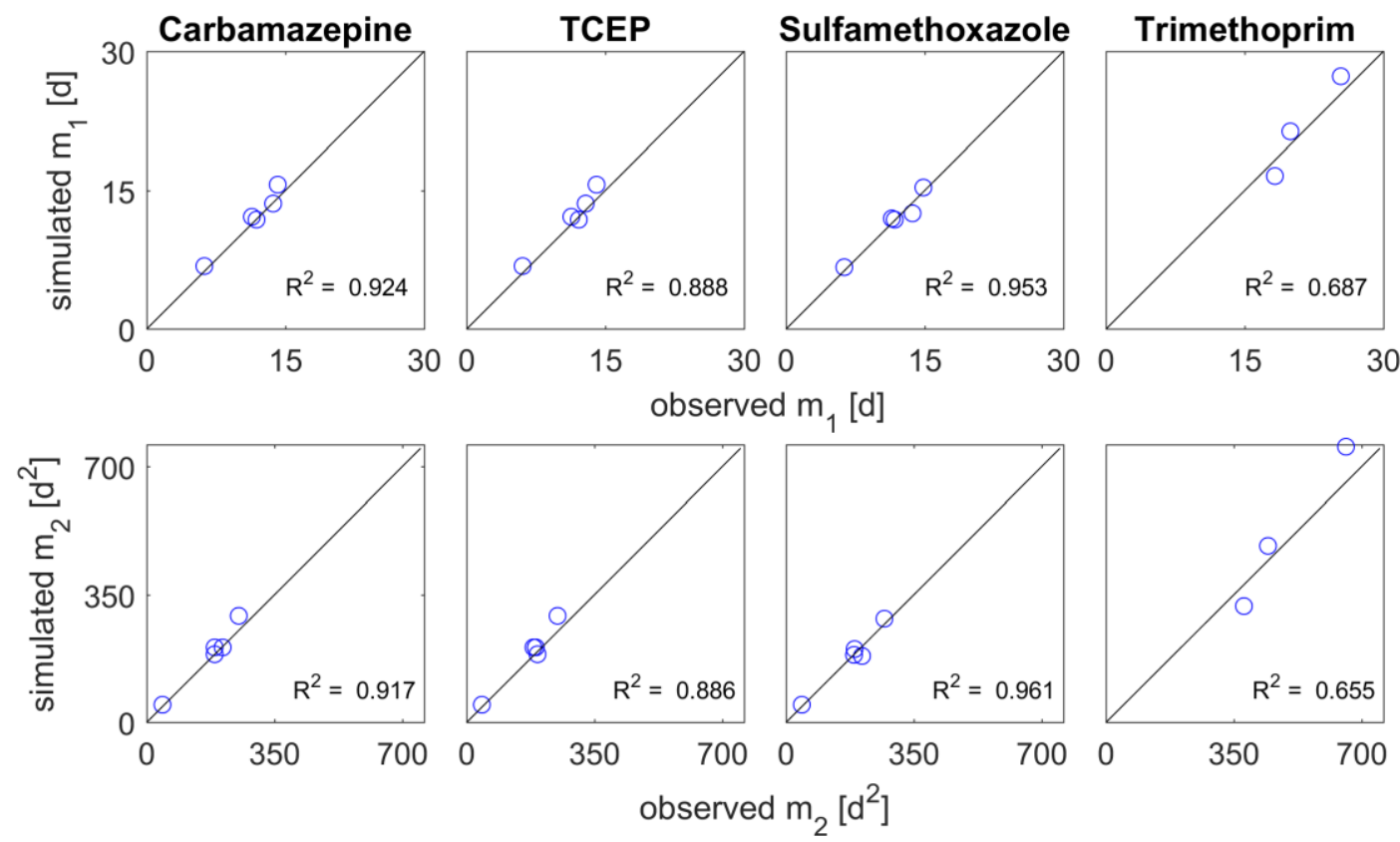

Figure 6. Observed vs. simulated first $\left(\mathrm{m}_{1}\right)$ and second $\left(\mathrm{m}_{2}\right)$ normalized moments of the breakthrough curves of the trace organic chemicals carbamazepine, sulfamethoxazole, and trimethoprim at all sensor locations. 

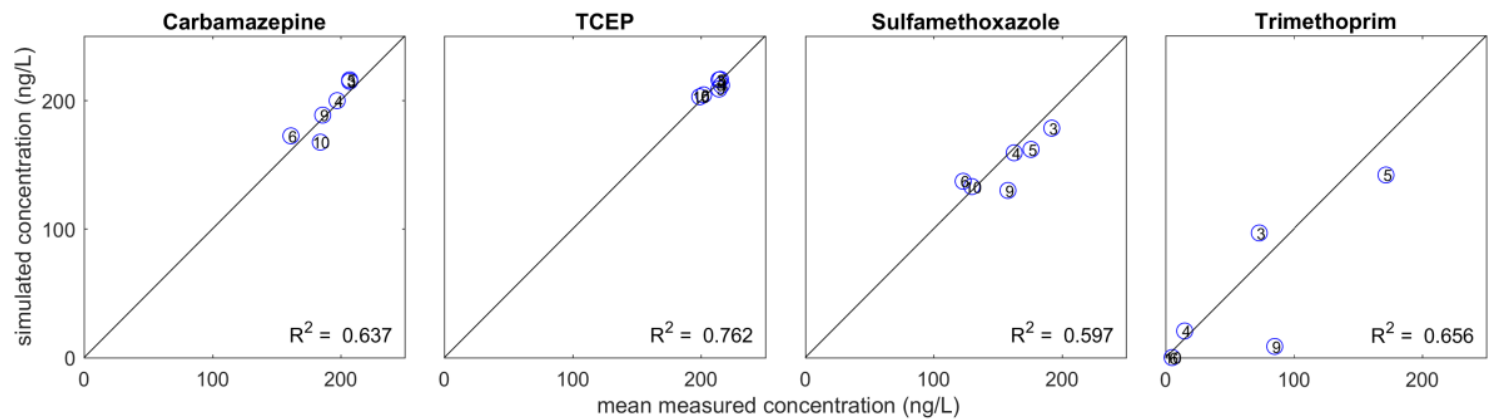

Figure 7. Comparison of simulated and measured trace organic chemical concentrations at all sensor locations during the second sampling campaign. 
Table 1. Selected physiochemical properties of trace organic chemicals analyzed in this study.

\begin{tabular}{cccccccccc}
\hline Compound & Classification & $\begin{array}{c}\mathbf{M W} \\
{[\mathbf{g} / \mathbf{m o l}]}\end{array}$ & Charge & $\boldsymbol{p} \boldsymbol{K}_{\boldsymbol{a}}$ & $\begin{array}{c}\boldsymbol{L o g} \\
\boldsymbol{K}_{\boldsymbol{~} w}\end{array}$ & $\begin{array}{c}\lambda^{\mathrm{a}} \\
{\left[\mathbf{d}^{-1}\right]}\end{array}$ & $\begin{array}{c}\lambda^{\mathrm{b}} \\
{\left[\mathbf{d}^{-1}\right]}\end{array}$ & $\begin{array}{c}\lambda^{\mathrm{c}} \\
{\left[\mathbf{d}^{-1}\right]}\end{array}$ & $\begin{array}{c}\boldsymbol{K}_{\boldsymbol{d}}{ }^{\mathrm{d}} \\
{[\mathbf{L} / \mathbf{k g}]}\end{array}$ \\
\hline Carbamazepine & Anticonvulsant & 236.3 & Neutral & 13.94 & 2.25 & $0 ; 0$ & $0.033\left(\mathrm{R}^{2}=0.95\right)$ & $0.035\left(\mathrm{R}^{2}=0.97\right)$ & 0.03 \\
Diphenhydramine & Antihistamine & 255.4 & Positive & 8.98 & 3.21 & $0 ; 0$ & - & - & $61^{\mathrm{e}}$ \\
Sulfamethoxazole & Antibiotic & 253.3 & Negative & 5.6 & 0.89 & $0.4 ; 0.049$ & $0.039\left(\mathrm{R}^{2}=0.79\right)$ & $0.051\left(\mathrm{R}^{2}=0.77\right)$ & 0 \\
TCEP & Flame retardant & 285.5 & Neutral & - & 1.44 & $0 ; 0$ & $0.011\left(\mathrm{R}^{2}=0.80\right)$ & $0.013\left(\mathrm{R}^{2}=0.81\right)$ & 0.03 \\
Trimethoprim & Antibiotic & 290.3 & Positive & 7.12 & 0.91 & $0.1 ; 0.01$ & - & - & 1.82 \\
\hline
\end{tabular}

${ }^{a}$ Biotransformation rate constants used in $1^{\text {st }}$ simulation of the unsaturated (oxidizing conditions) and saturated (reducing conditions) zone.

Values adapted from Burke et al. (2014b) and Regnery et al. (2015).

${ }^{\mathrm{b}}$ First-order biotransformation rate constants derived for the saturated zone of the 2D tank representing predominantly reducing conditions.

${ }^{\mathrm{c}}$ First-order biotransformation rate constants derived for the combined unsaturated and saturated zones of the 2D tank representing a sequence of oxidizing and reducing conditions.

${ }^{\mathrm{d}}$ Linear sorption. Values adapted from Drewes et al. (2015) for sand with $1 \%$ clay, $4 \%$ silt, $95 \%$ sand, $\mathrm{pH} 7.7, \mathrm{f}_{\mathrm{oc}} 0.1 \%, \mathrm{CEC}_{2} \mathrm{mmol}^{+} \mathrm{kg}^{-1}$.

${ }^{\mathrm{e}}$ Adapted from Wu et al. (2010b) for sandy soil with $9.7 \%$ clay, $3.2 \%$ silt, $87.1 \%$ sand, $\mathrm{pH} 5.1, \mathrm{f}_{\mathrm{oc}} 2.7 \%$. 
Table 2. Properties of the soils used in the 2D tank and selected modeling parameters.

\begin{tabular}{llcc}
\hline Soil properties & Unit & Granusil \#70 & MAR field soil \\
\hline Soil type & - & Sand & Sand \\
Fraction of sand & {$[\%]$} & 100 & 96 \\
Fraction of fines $(<0.075 \mathrm{~mm})$ & {$[\%]$} & 0 & 4 \\
Fraction of organic carbon $\left(f_{o c}\right)$ & {$[\%]$} & 0.1 & 0.3 \\
$\mathrm{pH}$ & - & 7.2 & 7.5 \\
Cation exchange capacity $(C E C)$ & {$\left[\mathrm{mmol}^{+} \mathrm{kg}^{-1}\right]$} & $2.7^{\mathrm{a}}$ & 77.4 \\
Dry bulk density $\left(\rho_{b}\right)$ & {$\left[\mathrm{g} \mathrm{cm}^{-3}\right]$} & 1.60 & 1.48 \\
Effective size $\left(D_{10}\right)$ & {$\left[\mathrm{mm}^{2}\right.$} & 0.12 & 0.48 \\
Uniformity coefficient $D_{60} / D_{l 0}\left(C_{u}\right)$ & - & 1.71 & 2.90 \\
Coefficient of gradation $\left(C_{c}\right)$ & - & 1.29 & 0.81 \\
Residual water content $\left(\Theta_{r}\right)$ & {$\left[\mathrm{g} \mathrm{g}^{-1}\right]$} & 0.037 & 0.075 \\
Air entry value $(A E V)$ & {$\left[\mathrm{cm} \mathrm{H}_{2} \mathrm{O}\right]$} & 41.2 & 22 \\
Porosity $(\phi)$ & - & 0.396 & 0.283 \\
Saturated hydraulic conductivity $(K)$ & {$\left[\mathrm{m} \mathrm{s}^{-1}\right]$} & $2.1 \times 10^{-4}$ & $1.8 \times 10^{-4}$ \\
& & & \\
FEFLOW parameters & & & $10^{-3}$ \\
\hline Longitudial dispersivity $\left(\alpha_{L}\right)$ & {$\left[\mathrm{m}^{-3}\right.$} & $10^{-4}$ & $10^{-4}$ \\
Transverse dispersivity $\left(\alpha_{T}\right)$ & {$\left[\mathrm{m}^{-4}\right.$} & $10^{-9}$ & $10^{-9}$ \\
Molecular diffusion coefficient & {$\left[\mathrm{m}^{2} \mathrm{~s}^{-1}\right]$} &
\end{tabular}

${ }^{a}$ Adapted from Darland (1996). 
Table 3. Selected water quality parameters for feed water (i.e., dechlorinated tap water) and intermediate sampling locations (clusters \#3, \#8, \#10) in the saturated zone of the synthetic aquifer $(\mathrm{n}=8)$.

\begin{tabular}{lcccc}
\hline & Feed water & Cluster \#3 & Cluster \#8 & Cluster \#10 \\
\hline $\mathrm{pH}$ & $7.7 \pm 0.2$ & - & - & $7.6 \pm 0.1^{\mathrm{a}}$ \\
$\mathrm{DO}\left[\mathrm{mg} \mathrm{L}^{-1}\right]$ & $6.1 \pm 2.7$ & - & - & $(3.3 \pm 1.7)^{\mathrm{a}}$ \\
$\mathrm{DOC}\left[\mathrm{mg} \mathrm{L}^{-1}\right]$ & $1.6 \pm 0.5$ & $1.2 \pm 0.4$ & $1.4 \pm 0.3$ & $1.1 \pm 0.1$ \\
UVA [m & & $0.7 \pm 0.3$ & $2.1 \pm 0.8$ & $1.5 \pm 0.3$ \\
$\mathrm{SUVA}\left[\mathrm{L} \mathrm{mg}^{-1} \mathrm{~m}^{-1}\right]$ & $0.9 \pm 0.4$ & $0.6 \pm 0.1$ & $1.5 \pm 0.3$ & $1.4 \pm 0.3$ \\
$\mathrm{TN}\left[\mathrm{mg} \mathrm{L}^{-1}\right]$ & $0.6 \pm 0.0$ & $0.6 \pm 0.1$ & $0.5 \pm 0.2$ & $0.6 \pm 0.0$ \\
$\mathrm{NH}_{4}-\mathrm{N}\left[\mathrm{mg} \mathrm{L}^{-1}\right]$ & $<0.008(\mathrm{DL})$ & - & - & $<0.008(\mathrm{DL})$ \\
$\mathrm{NO}_{3}^{-}-\mathrm{N}\left[\mathrm{mg} \mathrm{L}^{-1}\right]$ & $0.3 \pm 0.1$ & $0.4 \pm 0.1$ & $0.2 \pm 0.1$ & $0.3 \pm 0.1$ \\
$\mathrm{SO}_{4}^{2-}\left[\mathrm{mg} \mathrm{L}^{-1}\right]$ & $102.1 \pm 12.5$ & $110.0 \pm 10.4$ & $109.3 \pm 8.5$ & $108.3 \pm 14.2$ \\
$\mathrm{Mn}^{2+}\left[\mathrm{mg} \mathrm{L}^{-1}\right]$ & $<0.0003(\mathrm{DL})$ & $0.01 \pm 0.01$ & $0.11 \pm 0.03$ & $0.02 \pm 0.02$ \\
$\mathrm{Fe}^{2+}\left[\mathrm{mg} \mathrm{L}^{-1}\right]$ & $<0.0004(\mathrm{DL})$ & $<0.0004(\mathrm{DL})$ & $<0.0004(\mathrm{DL})$ & $0.01 \pm 0.01$ \\
\hline
\end{tabular}

${ }^{\mathrm{a}}$ Measured in samples collected at the 2D tank outflow. $\mathrm{DL}=$ detection limit. 